\title{
MSWI bottom ash as eco-aggregate in cement mortar design
}

\author{
Z. Pavlík, M. Keppert, M. Pavlíková, J. Fořt, O. Michalko \\ \& R. Černý \\ Department of Materials Engineering and Chemistry, Faculty of Civil \\ Engineering, Czech Technical University in Prague, Czech Republic
}

\begin{abstract}
The applicability of bottom ash (BA) generated by municipal solid waste incineration (MSWI) as partial replacement of silica aggregate in cement mortar mix design is researched in the paper. In order to evaluate the effect of BA admixture on properties of cement mortar, the reference cement mortar without BA is studied as well. For the applied BA and silica aggregate, grain size curves are measured using standard sieve method. The particle size distribution of both aggregates is studied also by laser diffraction method. Basic material properties of cement mortar, namely the bulk density, matrix density, and total open porosity, are measured using gravimetric method combined with helium pycnometry. For the studied BA, also the powder density in the dry state is measured on gravimetric principle. The influence of BA admixture on mechanical performance of the developed mortars is evaluated by measurement of compressive strength, bending strength and dynamic Young's modulus that is accessed by ultrasonic pulse method as well as resonance method. Since the durability of building materials is except of the other harmful effects related to the rate of possible moisture transport into their inner structure, moisture diffusivity, sorptivity and water absorption coefficient are analysed using standard sorptivity test. For explanation of the obtained data, the pore size distribution is measured on mercury porosimetry principle. Experimental results proved the applicability of the applied BA as partial silica aggregate replacement in composition of cement mortar, whereas the reuse of studied MSWI residue as mortar aggregate represents an interesting alternative to final landfill disposal. Keywords: bottom ash, silica aggregate replacement, cement mortar, durability and mechanical properties.
\end{abstract}




\section{Introduction}

From the point of view of ecological and sustainable aspects, the building industry is recognized as the largest consumer of natural resources and significant producer of waste. In order to preserve clean environment, there is a need for improvement of existing production technologies of building materials by transforming them into sustainable and environmentally friendly.

Since the building materials are manufactured mainly on a natural basis, their production has harmful effect on the living environment quality. Hence, the ways of the natural sources savings are searched. One of important ways, widely applied in civil engineering for long years, is to replace natural sources with secondary materials, i.e. waste from other processes. Global growth in the production and manufacturing sectors leads to the accumulation and accelerating the output of industrial waste. This waste must be properly managed and treated without causing any harmful environmental effects. Also on this account, material engineers are left with the challenge of managing the industrial waste.

There can be found many examples of application of industry waste products in production of building materials in literature. For example fly ash (FA) and BA from coal combustion can be incorporated into cement materials as binder to replace cement or as an aggregate, as a partial natural sand replacement, according to the grain-size distribution of the material utilization in mortar or in structural concrete [1-5]. The influence of coal BA, granulated blast furnace slag, and a combination of both materials which were used as fine aggregate replacement in concrete mix design was studied by Yüksel et al. [6]. They concluded that durable concrete can be produced by using granulated blast furnace slag and BA as fine aggregate. Also microsilica as a by-product of silica and ferrosilica production finds use in the concrete industry. It causes concrete's higher mechanical strength and chemical and temperature resistivity [7, 8]. Since Microsilica improves also the rheological properties of fresh concrete, it is often used for the production of self compacting concrete [9]. Waste ceramic materials become also cheap alternative as supplementary binder in concrete. The ceramic industry often produces calcined clays that result from burning illite-group clays which are commonly used in the production of red-clay ceramic products. A portion of these products (which amounts up to $2 \%$ depending on producer and country) is discarded as scrap, thus constitutes industrial waste. The residues of ceramic bricks and floor and roof tiles ground to a suitable fineness can though become active pozzolanas and can be used in mortars and concrete design [10, 11]. Also the quarry dust has been used successfully in concrete, pavement construction $[12,13]$. Quarry dust (QD) is crushed dust, produced during the breaking of stone boulders in stone crushers for producing coarse aggregates. The quarry dust consists of excess fines and is considered as a waste material which is normally dumped in bulk quantities around the quarry plants and causes environmental pollution [14].

Instead of the above given waste products already being reused in the building industry, there are also waste materials, which are still not frequently used in practise, because their possible application brings a number of potential 
problems from the point of view of their toxicity, chemical stability, durability etc. For example Cyr and Ludmann [15] studied the possibility of the use of low risk meat and bone meal BA in mortars as sand replacement. Meat and bone meal (MBM) is a by-product of the food industry, obtained by the removal of fat (rendering) from mammal carcasses by a process of crushing, cooking and grinding. In Europe, more than $3 \mathrm{M}$ tons of MBM are produced annually. Until 1994, most of the MBM produced in Europe was used as animal feed, fertilizer and in other industrial applications. However, since the transmissible spongiform encephalopathy (TSE) crisis, MBM has been progressively banned from animal feed. As a consequence, MBM must be treated by incineration or other proper techniques. Cyr and Ludmann found that the BA coming from incineration of MBM could be used in cement-based materials and present a promising way of reusing this residue. Razak et al. [16] investigated incineration BA for production of controlled low-strength materials (CLSM). They found that there is good potential for the use of industrial waste incineration BA in CLSM. The same results were published also by Naganathan et al. [14].

It is without doubt that waste management becomes one of the most actual problems of present society, whereas the amount of disposed waste will be strictly limited in the near future. On that account, especially the combustion method of the waste treatment will become more popular and the increase of the amount of the incineration waste products can be expected. Hence various methods of using the BA and FA need to be developed. Incineration byproducts, if reused, will offer many advantages, ensure sustainability, reduces pollution and environmental degradation, generate revenue, and preservation of natural resources, etc. [16]. Solid residuals from waste incineration process are subjected in the last decade to an intensive research focused on their possible application as new concrete mineral admixtures, whereas the residues from the municipal solid waste incineration are most often studied [17]. These materials can play role of active as well of non-active mineral admixture as stated for example in [18, 19].

Since the results of the above given research are very promising from the point of view of the use of MSWI materials in materials production, we focused in the presented paper on experimental research of possible partial silica sand replacement by MSWI BA in composition of cement based composites. This analysis should contribute to the wider utilization of MSWI products in building materials production with lower impact of environment.

\section{Researched materials}

Two types of cement composites (mortars) containing MSWI BA as partial silica sand replacement denoted CMA 10 and CMA 40 were analysed, together with the reference material CMR without MSWI BA addition. The mortars were prepared with Portland cement CEM I $42.5 \mathrm{R}$ as the main binder. The BA was firstly sieved, whereas only fraction $0-4 \mathrm{~mm}$ was used in this work in state "as received". The composition of studied materials is given in Table 1. 
Table 1: $\quad$ Composition of researched materials.

\begin{tabular}{|c|c|c|c|c|}
\hline \multicolumn{2}{|c|}{ Material } & CMR & CMA 10 & CMA 40 \\
\hline Portland cement CEM 42.5 R & $\mathrm{g}$ & 500 & 500 & 500 \\
\hline MSWI BA & $\mathrm{g}$ & 0 & 150 & 600 \\
\hline Silica sand 0/4 mm & $\mathrm{g}$ & 1500 & 1350 & 900 \\
\hline Water & $\mathrm{ml}$ & 260 & 260 & 260 \\
\hline
\end{tabular}

The used BA is waste product of the MSWI plant Termizo Liberec, located in the northern part of Czech Republic (see Figure 1). The amount of the processed municipal waste is $96000 \mathrm{t} /$ year, operation time is 8000 hours/year. The reduction of waste by volume is $1 / 10$ and $1 / 3$ by mass.

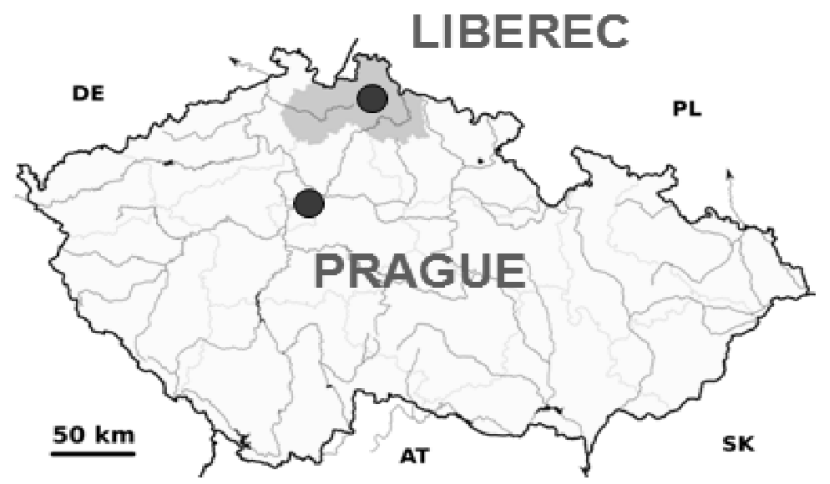

Figure 1: $\quad$ Location of MSWI plant Termizo.

For the BA, there were measured basic material characteristics as powder density, matrix density, $\mathrm{pH}$ of leachate, solubility and pozzolanic activity. The basic properties of BA are summarized in Table 2 .

Table 2: $\quad$ Basic physical properties of applied BA.

\begin{tabular}{|c|c|c|c|c|}
\hline $\begin{array}{c}\text { Powder } \\
\text { density } \\
\left(\mathrm{kg} / \mathrm{m}^{3}\right)\end{array}$ & $\begin{array}{c}\text { Matrix } \\
\text { density } \\
\left(\mathrm{kg} / \mathrm{m}^{3}\right)\end{array}$ & $\begin{array}{c}\mathrm{pH} \\
\text { leachate }\end{array}$ & $\begin{array}{c}\text { Solubility } \\
(\%)\end{array}$ & $\begin{array}{c}\text { Pozzolanic } \\
\text { activity }\end{array}$ \\
\hline 1180 & 2630 & 9.3 & 10 & yes \\
\hline
\end{tabular}

SEM image of the Termizo BA is given in Figure 2. Here, also the EDS analysis was done in order to get rough estimate of its composition. We indicated silicates, Al, Fe, and Ca oxides, scrap glass, calcium sulphate, etc. 


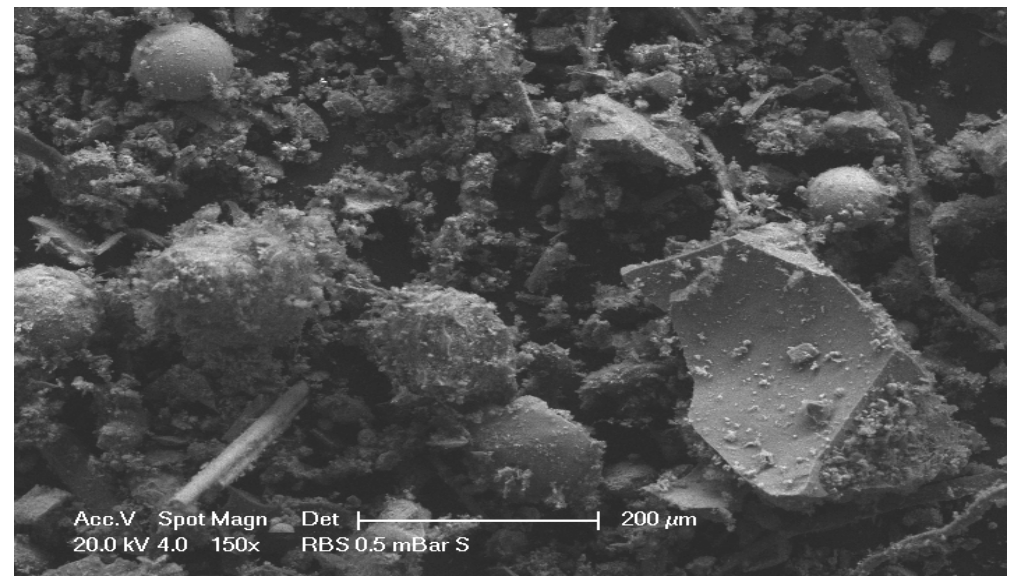

Figure 2: $\quad$ SEM image of BA from MSWI plant Termizo.

\section{Experimental methods}

\subsection{Particle size distribution}

The particle size distribution was measured on laser diffraction principle using the device Analysette 22 Micro Tec plus. This device uses red laser for measurement of bigger particles and green laser for finer particles. Since the laser analyser allows measurement of grain size up to $2 \mathrm{~mm}$, it was necessary to perform also the common sieving tests.

\subsection{Basic material properties}

For the researched mortars, measurements of bulk density, matrix density, and total open porosity were performed. The experiments were done on 5 cubic samples of side $50 \mathrm{~mm}$. The relative expanded uncertainty of applied testing method was $5 \%$ and was mainly due to material nonhomogeneity. Bulk density was determined from the measurement of sample sizes (using digital length meter) and its dry mass. The matrix density was accessed by helium pycnometry using apparatus Pycnomatic ATC (Thermo Scientific). The accuracy of the gas volume measurement using this device is $\pm 0.01 \%$ from the measured value, whereas the accuracy of used analytical balances is $\pm 0.0001 \mathrm{~g}$. On the basis of bulk density and matrix density measurements, the total open porosity $\psi(-)$ was calculated using eqn (1)

$$
\psi=100\left(1-\rho_{b} / \rho_{m a t}\right),
$$

where $\rho_{\text {mat }}\left(\mathrm{kg} / \mathrm{m}^{3}\right)$ is matrix density, and $\rho_{b}\left(\mathrm{~kg} / \mathrm{m}^{3}\right)$ bulk density. 


\subsection{Mechanical properties}

The bending strength of cured mortars that were stored 28 days in relative humidity of $100 \%$ was determined using the procedure described in ČSN EN 12390-5 [20]. For the measurement, prismatic samples having dimensions of $160 / 40 / 40 \mathrm{~mm}$ were used. The compressive strength was measured according to the ČSN EN 12390-3 [21] on the portions of prisms broken in bending test; the loading area was $40 \times 40 \mathrm{~mm}$.

Young's modulus can be measured using static or dynamic methods. Static methods are based on direct measurements of stresses and strains during mechanical tests, whereas Young's modulus is determined from the slope of the linear region of the stress-strain curve. Dynamic methods are broadly classified as pulse ultrasonic methods and resonance methods [22]. In this paper, both dynamic methods were applied. In the performed experiments, the samples were cured prisms having dimensions of $300 / 40 / 20 \mathrm{~mm}$ and the measurements were performed in longitudinal direction.

The ultrasonic pulse method is based on measurement the travel time of ultrasonic wave passing through the material. See Figure 3 for the measurement scheme of the applied device DIO 562.

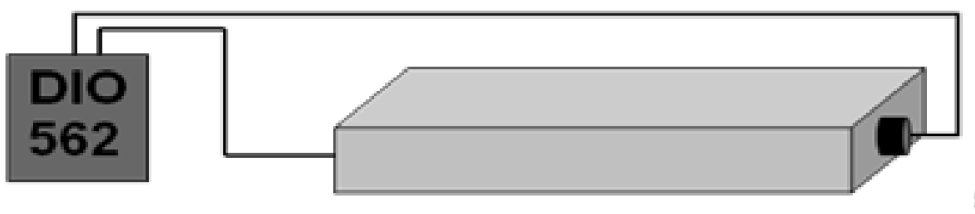

$50 \mathrm{kHz}$

Figure 3: Scheme of the ultrasonic pulse method.

The relationship between dynamic Young's modulus $E_{u}(\mathrm{MPa})$, wave velocity $v(\mathrm{~m} / \mathrm{s})$ and bulk density $\rho_{b}\left(\mathrm{~kg} / \mathrm{m}^{3}\right)$ is given by eqn (2)

$$
E_{u}=\rho_{b} v^{2} .
$$

The resonance method is based on determination of system's first resonation frequency by help of piezoelectric resonator applied to the sample. The scheme of the method is given in Figure 4.

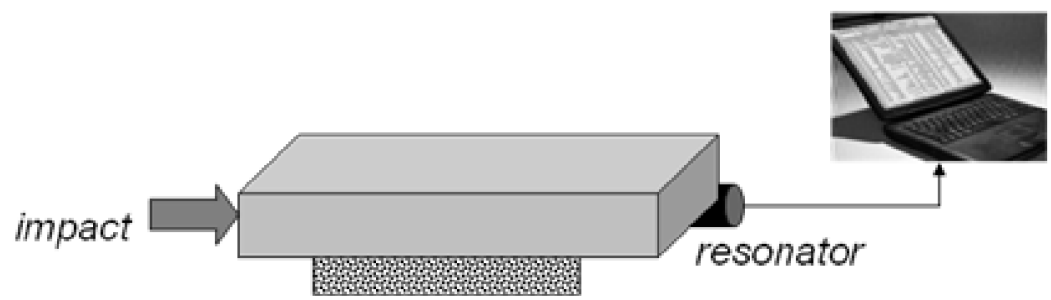

Figure 4: Scheme of the ultrasonic resonance method. 
The Young's modulus $E_{r}(\mathrm{MPa})$ is then expressed using eqn (3)

$$
E_{r}=4 \rho_{b} l^{2} f^{2},
$$

respectively eqn (4)

$$
E_{r}=4 \frac{m}{a b} l f^{2},
$$

where $l(\mathrm{~m})$ is the sample length, $f(\mathrm{~Hz})$ the longitudinal resonance frequency, $a$ (m) the height and $b(\mathrm{~m})$ the width of the studied sample in case of rectangular cross-section.

\subsection{Sorptivity test}

Sorptivity test is based on free water 1-D intake experiment [23] that represents the simplest technique for the characterization of the ability of porous materials to absorb water and transport it by capillary forces. Using this experiment, the water transport in the studied material is characterised by water absorption experiment and sorptivity. Sorptivity $S\left(\mathrm{~m} / \mathrm{s}^{-1 / 2}\right)$ is defined as

$$
I=S \cdot t^{1 / 2},
$$

where $I(\mathrm{~m})$ is the cumulative absorption of water and $t(\mathrm{~s})$ the time of absorption. Eqn (1) is a simplification of the general expression for the cumulative mass of water in terms of the square-root-of-time rule that is commonly employed in the diffusion theory [23], which is obtained by dividing the original equation

$$
i=A \cdot t^{1 / 2},
$$

by the density of water $\rho_{w}\left(\mathrm{~kg} / \mathrm{m}^{3}\right)$. In eqn (6), $i\left(\mathrm{~kg} / \mathrm{m}^{2}\right)$ is the cumulative mass of water and $A\left(\mathrm{~kg} / \mathrm{m}^{2} \mathrm{~s}^{1 / 2}\right)$ the water absorption coefficient that is related to the sorptivity according to the eqn (7)

$$
A=S \cdot \rho_{w} .
$$

Setup for measurement of water absorption coefficient consists of tank filled with water, and the material sample, water and vapour-proof insulated on four lateral sides, hung on automatic balance and immersed $1-2 \mathrm{~mm}$ in the water. The automatic balance allows continuous recording of increase of mass of the sample. On the basis of measured results, the water absorption coefficient can be measured and water sorptivity calculated. For our measurement, 5 cubic samples of each tested material were tested, whereas the typical sample size was $50 \times 50$ x $50 \mathrm{~mm}$. The samples were insulated on all lateral sides by epoxy resin in order to ensure $1-\mathrm{D}$ water transport and dried at $100^{\circ} \mathrm{C}$.

\subsection{Mercury porosimetry analysis}

The evaluation of obtained results was done regarding to the pore size distribution that was studied on mercury porosimetry principle. For the 
measurement, porosimeters Pascal 140 and Pascal 440 Thermo Scientific were used. Within the evaluation of measured data, the circular cross section of capillaries was assumed.

\section{Results and discussion}

Particle size distribution of both applied aggregates determined by laser diffraction method and sieving analysis is presented in Figures 4, 5. Looking at the data measured by laser diffraction in the particle size range $0-1 \mathrm{~mm}$, one can see that the bottom ash is systematically finer than silica sand that exhibited majority of its particles in the range $100-1000 \mu \mathrm{m}$. The same feature was observed also in the case of sieving analysis, where the whole range of particle size was analysed.

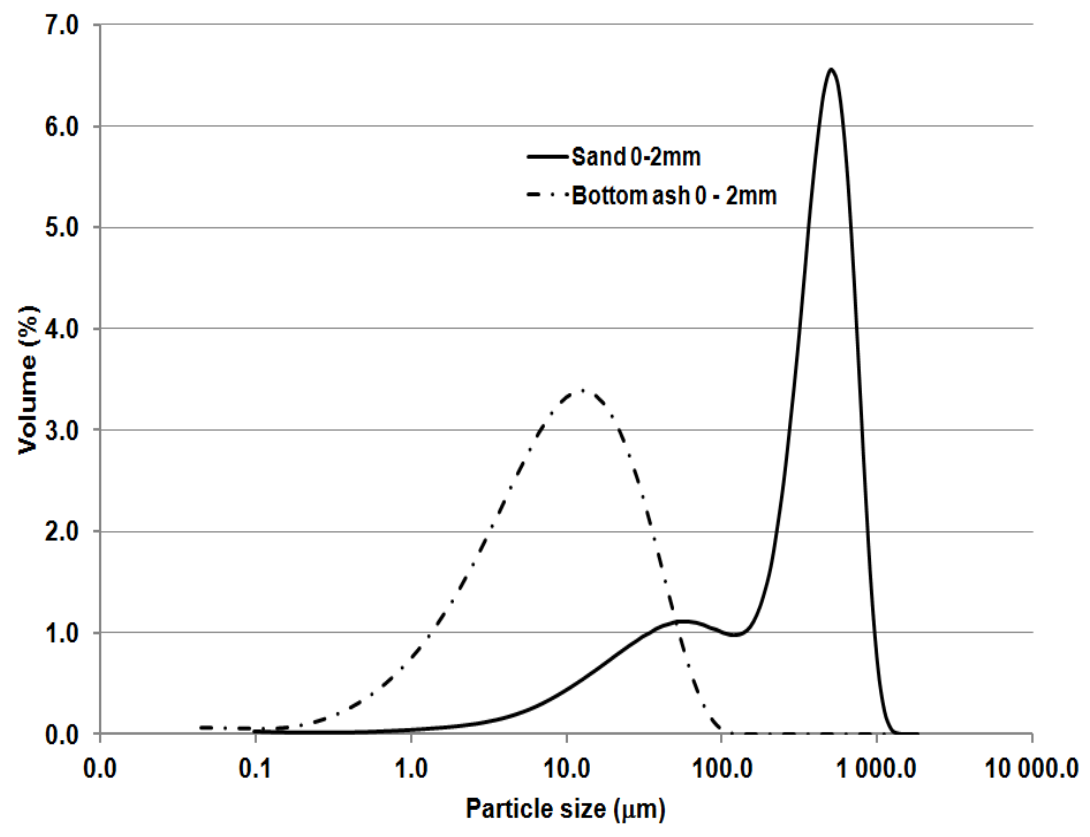

Figure 5: $\quad$ Particle size distribution measured by laser diffraction.

Basic material properties of researched composites are given in Table 3. We can see that the partial replacement of silica sand led to the decrease in bulk density of the developed mortars in comparison with the reference material. On the other hand, the matrix density remained the same. The decrease in bulk density was then reflected in the increase of the total open porosity of mortars containing BA. 
Table 3: $\quad$ Basic material properties of studied composites.

\begin{tabular}{|c|c|c|c|}
\hline & CMR & CMA 10 & CMA 40 \\
\hline Matrix density $\left(\mathrm{kg} / \mathrm{m}^{3}\right)$ & 2662 & 2671 & 2650 \\
\hline Bulk density $\left(\mathrm{kg} / \mathrm{m}^{3}\right)$ & 2105 & 2013 & 1911 \\
\hline Total open porosity $(\%)$ & 20.9 & 24.6 & 27.9 \\
\hline
\end{tabular}

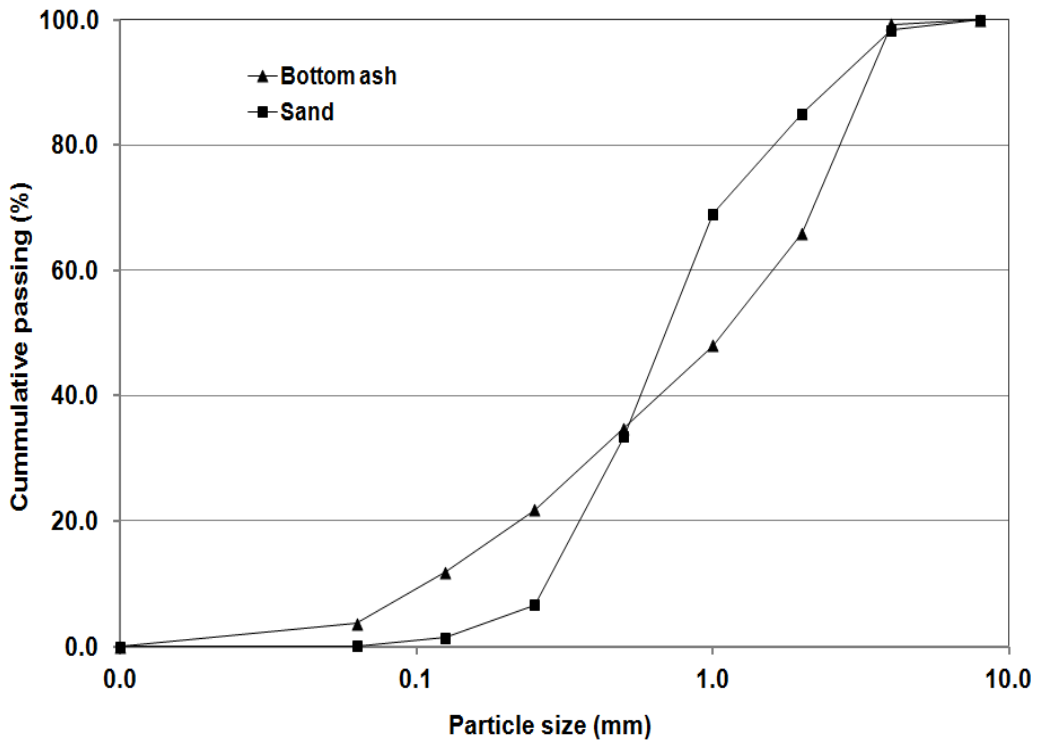

Figure 6: $\quad$ Particle size distribution measured by sieving test.

Accessed mechanical properties are summarized in Table 4. The compressive and bending strengths were systematically enhanced with increasing amount of admixed BA. It is generally recognized that Young's modulus of cementitious composites is increasing with increasing strength but this is not that case. The dynamic Young's modulus values acquired by two independent methods featured good agreement; the BA admixing in mortar CMA 10 caused Young's modulus reduction by ca $8 \%$ and in CMA 40 by ca $13 \%$. The explanation lies in very different character of BA compared to natural sand; BA is porous and its strength and own Young's modulus is limited which resulted to decrease of Young's modulus of mortars with BA compared to reference material.

Results of mercury porosimetry analysis are presented in Figure 7. These cumulative curves are in a good agreement with the total open porosity values accessed using gravimetric measurement of bulk density and helium pycnometry. On the other hand, they do not support the results of compressive and bending strength measurement. 
Table 4: $\quad$ Mechanical properties.

\begin{tabular}{|c|c|c|c|}
\hline & CMR & CMA 10 & CMA 40 \\
\hline Compressive strength $(\mathrm{MPa})$ & 41.0 & 42.0 & 45.0 \\
\hline Bending strength $(\mathrm{MPa})$ & 6.5 & 7.0 & 7.5 \\
\hline Young's modulus - pulse method $(\mathrm{GPa})$ & 23.9 & 19.76 & 19.5 \\
\hline Young's modulus - resonance method $(\mathrm{GPa})$ & 25.9 & 21.72 & 19.4 \\
\hline
\end{tabular}

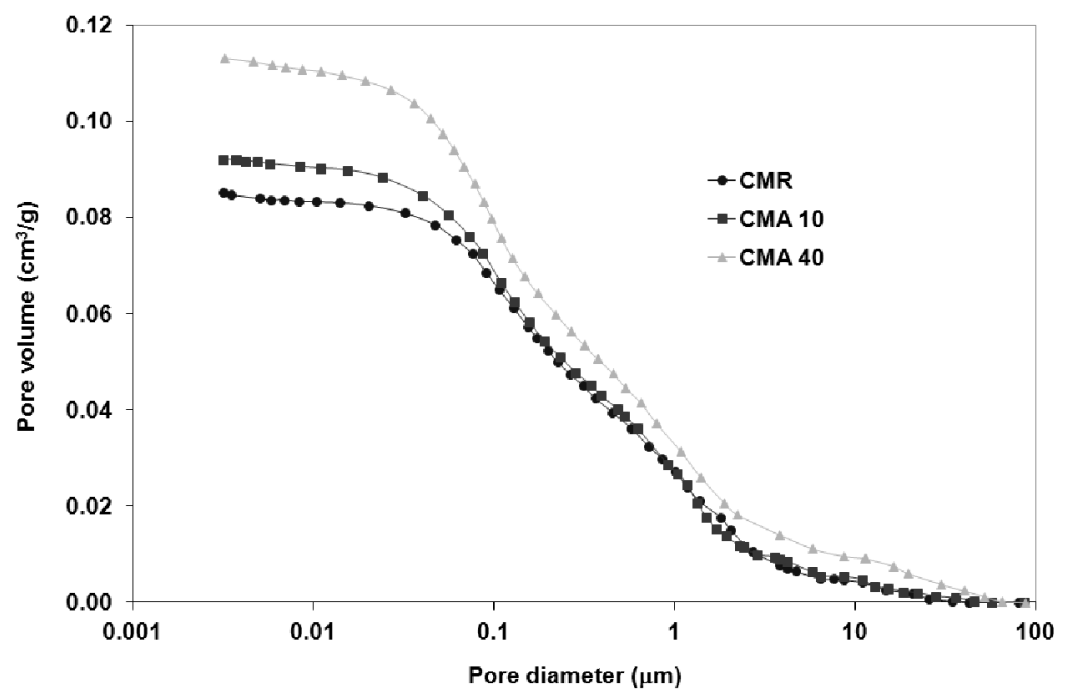

Figure 7: $\quad$ Pore size distribution of studied mortars.

Water sorptivity and water absorption coefficient data are given in Table 5 . Here, the liquid water transport was systematically slower for materials modified by BA addition in comparison with the reference composite mixture. One can see analogy of this materials behaviour as in the case of compressive and bending mechanical loading.

Table 5: $\quad$ Liquid water transport properties.

\begin{tabular}{|c|c|c|c|}
\hline & CMR & CMA 10 & CMA 40 \\
\hline Water absorption coefficient $\left(\mathrm{kg} / \mathrm{m}^{2} \mathrm{~s}^{1 / 2}\right)$ & 0.017 & 0.015 & 0.011 \\
\hline Water sorptivity $\left(\mathrm{m}^{2} / \mathrm{s}^{1 / 2}\right)$ & $1.70 \mathrm{E}-5$ & $1.50 \mathrm{E}-5$ & $1.10 \mathrm{E}-5$ \\
\hline
\end{tabular}

\section{Conclusions}

Experimental results presented in this paper proved the potential applicability of applied MSWI BA in cement based composites design. The admixture of MSWI 
BA improved the compressive and bending strength of modified composites in comparison with the reference material. The application of MSWI BA also limited the possible liquid water transport into the studied materials. On the other hand, the elastic mechanical properties decreased with BA addition. Therefore, more detailed analysis is still needed for wider use of MSWI BA as silica sand replacement in building industry.

\section{Acknowledgement}

This research has been supported by the Czech Science Foundation, under project No. P104/11/0438.

\section{References}

[1] Andrade, L.B., Rocha, J.C., Cheriaf, M., Evaluation of concrete incorporating bottom ash as a natural aggregates replacement. Waste Management, 27, pp. 1190-1199, 2006.

[2] Cheriaf, M., Péra, J., Rocha, J.C., Pozzolanic properties of pulverized coal combustion bottom ash. Cement and Concrete Research, 29, pp. 13871391.

[3] Ghafoori, N., Bucholc, J., Investigation of lignite-based bottom ash for structural concrete. Journals of Materials in Civil Engineering, 8(3), pp. 128-137, 1996.

[4] Kim, H.K., Jeon, J.H., Lee, H.K., Flow, water absorption, and mechanical characteristics of normal and high-strength mortar incorporating fine bottom ash aggregates. Construction and Building Materials, 26, pp. 249256, 2012.

[5] Wei, L., Naik, T.R., Golden, D.M., Construction materials made with coal combustion by/products. Cement Concrete and Aggregates, 16, pp. 36-42, 1994.

[6] Yüksel, I., Turhan. B., Özkan. Ö., Durability of concrete incorporating nonground blast furnace slag and bottom ash as fine aggregate. Building and Environment, 42, pp. 2651-2659, 2007.

[7] Ji, T., Preliminary study on the water permeability and microstructure of concrete incorporating nano- $\mathrm{SiO}_{2}$. Cement and Concrete Research, 35, pp. 1943-1947, 2005.

[8] Jo, B.W., Kim. C.H., Tae. G.H., Characteristics of cement mortar with nano- $\mathrm{SiO}_{2}$ particles. Construction and Building Materials, 21, pp. 1351-5, 2007.

[9] Jalal, M., Mansouri, E., Sharifipour, M., Pouladkhan, A.R., Mechanical, rheological and microstructural properties of high performance selfcompacting concrete containing $\mathrm{SiO}_{2}$ micro and nanoparticles. Materials and Design, 34, pp. 389-400, 2012.

[10] O'Farrel, M., Sabir, B.B., Wild, S. Strength and chemical resistance of mortars containing brick manufacturing clays subjected to different treatments. Cement and Concrete Composites, 28, pp. 790-799, 2006. 
[11] Gonçalves, J.P., Taveres, L.M., Teledo Filho, R.D., Fairabaim, E.M.R., Performance evaluation of cement mortars modified with metakaolin or ground brick. Construction and Building Materials, 23, pp. 1971-1979, 2009.

[12] Ho D.W.S., Sheinn A.M.M., Ng C.C., Tam C.T. The use of quarry dust for SCC applications. Cement and Concrete Research, 32, pp. 505-11, 2002.

[13] Nataraja M.C., Nagaraj T.S., Reddy, A., Proportioning concrete mixes with quarry wastes. Cement Concrete and Aggregates, 23, pp. 81-87, 2001.

[14] Naganathan, S., Razak, H.A., Hamid, S.N.A., Properties of controlled lowstrength material made using industrial waste incineration bottom ash and quarry dust. Materials and Design, 33, pp. 56-63, 2012.

[15] Cyr, M. and Ludmann, Ch., Low risk meat bone meat (MBM) bottom ash in mortars as sand replacement. Cement and Concrete Research, 36, pp. 469-480, 2006.

[16] Razak, H.A., Naganathan, S., Hamid, S.N.A., Performance appraisal of industrial waste incineration bottom ash as controlled low-strength material. Journal of Hazardous Materials, 172, pp. 862-867, 2009.

[17] Sorlini, S., Abba, A., Collivignarelli, C., Recovery of MSWI and soil washing residues as concrete aggregates. Waste Management, 31, pp. 289 297, 2011.

[18] Bertolini, L., Carsana, M., Cassago, D., Quadrio Curzio, A., Collepardi, M., MSWI ashes as mineral additions in concrete. Cement and Concrete Research 34, pp. 1899-1906, 2004.

[19] Cheesman, C.R., Makinde, A., Bethanis, S., Properties of lightweight aggregate produced by rapid sintering of incinerator bottom ash. Resources, Conservation and Recycling 43, pp. 147-162, 2005.

[20] ČSN EN 12390-5, Testing of hardened concrete - Part 5: Bending strength, Czech Standardization Institute, Prague, 2007.

[21] ČSN EN 12390-3, Testing of hardened concrete - Part 3: Compressive strength, Czech Standardization Institute, Prague, 2002.

[22] Štubňa, I., Trník, A., Vozár, L., Determination of Young's modulus of ceramics from flexural vibration at elevated temperatures. Acta Acustica United with Acustica 97, pp. 1-7, 2011.

[23] Vejmelková, E., Pavlíková, M., Jerman, M., Černý, R., Free water intake as means of material characterization. Journal of Building Physics 33(1), pp. 29-44, 2009. 